\title{
5-HTTLPR polymorphism and anxious preoccupation in early breast cancer patients
}

\author{
Giulia Schillani ${ }^{1}$, Daniel Era1, Tania Cristante², Giorgio Mustacchi², \\ Martina Richiardi ${ }^{1}$, Luigi Grassi ${ }^{3}$, Tullio Giraldi ${ }^{1}$ \\ ${ }^{1}$ Department of Life Sciences, University of Trieste, Trieste, Italy \\ ${ }^{2}$ University of Trieste and Centro Sociale Oncologico, ASS1, Trieste, Italy \\ ${ }^{3}$ Section of Psychiatry, Department of Behavior and Communication, University of Ferrara, Ferrara, Italy
}

Radiol Oncol 2012; 46(4): 321-327.

Received 15 October 2011

Accepted 2 February 2012

Correspondence to: Giulia Schillani, Research Assistant, Department of Life Sciences, University of Trieste, Via L. Giorgieri 7, 34127 Trieste, Italy. Phone: +39040 5587947 ; Fax: +39040 577435; E-mail: gschillani@units.it

Disclosure: No potential conflicts of interest were disclosed.

Background. Difficulties in coping with cancer, and the accompanying anxious and depressive symptoms, have been shown to affect the mood and the quality of life in breast cancer patients. 5-Hydroxytryptamine Transporter Gene-linked Polymorphic Region (5-HTTLPR) functional polymorphism of serotonin transporter has been shown to influence the adaptation to stressful life events. The aim of this prospective study was therefore to examine the association of 5-HTTLPR with the mental adaptation to cancer diagnosis and treatment.

Patients and methods. Forty eight consecutive patients with early mammary carcinoma were evaluated at enrolment and at follow up after one and three months. The patients were characterized psychometrically using the Hospital Anxiety and Depression Scale (HADS) and the Mini-Mental Adjustment to Cancer Scale (Mini-MAC); 5-HTTLPR allelic variants were determined using PCR-based techniques.

Results. In women with early breast cancer, the mental adaptation to the disease was associated with high scores of avoidance and anxious preoccupation of Mini-MAC, which decreased with time at follow up. Anxious preoccupation decreased with time less in patients with the $S / S$ and $S / L$ genetic variant of 5 -HTTLPR as compared with the L/L carriers $(p=0.023)$, indicating gene - environment interactions.

Conclusions. These results indicate that the characterization of 5-HTTLPR allows the identification of breast cancer patients in greater risk of mental suffering, for which specific intervention may be focused; in case of drug therapy, they provide indications for the choice of most appropriate agent in a pharmacogenetic perspective.

Key words: breast cancer; mental adjustment to cancer; depression; anxiety; 5-HTTLPR polymorphism.

\section{Introduction}

A large literature indicates that facing a neoplastic disease is a challenging experience which deeply involves cognitive and emotional aspects of the individual. ${ }^{1-12}$ Coping with cancer requires a mental adaptation to the communication of diagnosis, to the choice between the alternatives for the subsequent adjuvant treatment, and to the follow-up. Specific modalities of mental adaptation to cancer, namely hopelessness-helplessness, fighting spirit, fatalism, avoidance and anxious preoccupation, have been shown by Greer et al. and Watson et al. to characterize the individual modalities of coping with the disease. ${ }^{13,14}$ While these modalities have evident implications for the quality of life of the patients, these investigators also reported an increased risk of death in women with high scores on the hopelessness-helplessness category of the Mental Adjustment to Cancer (MAC) Scale, and also on the Hospital Anxiety and Depression Scale (HADS) category of depression. ${ }^{13,14}$

The role of the genetic polymorphism in the response to treatment and survival for oncological 
patients is well known. ${ }^{15,16}$ However, the genetic polymorphism of serotonin transporter (SERT) in causing an increased risk of depression in subjects who experienced stressful life events is also known and it has been initially reported by Caspi et al. ${ }^{17} \mathrm{In}$ the prospective-longitudinal study of a representative birth cohort, the authors tested why stressful experiences lead to depression only in some subjects. A functional polymorphism, consisting in one or two copies of the short (S) allele of the 5-HTTLPR (5-Hydroxytryptamine Transporter Gene-linked Polymorphic Region) in the promoter region of the SERT gene, was found to increase the influence of stressful life events on the development of depression, representing gene - environment interactions. ${ }^{17}$ A large number of investigations have subsequently examined the associations of the development of mental disorders in a variety of psychological and psychiatric conditions with SERT polymorphism, evaluating the role played by the allelic variants of 5-HTTLPR, which are endowed with high $(\mathrm{L} / \mathrm{L})$ or low $(\mathrm{S} / \mathrm{S}, \mathrm{S} / \mathrm{L})$ functional activity and have a high penetrance in the populations examined. ${ }^{18}$

The most frequent oncological disease in women is breast cancer ${ }^{19,20}$ and the communication of breast cancer diagnosis, as well as the treatments subsequently performed, has been shown to be a constellation of significant stressful events, requiring adequate psychological adaptation by patients..$^{1-5}$ Different modalities of mental adaptation to cancer have been identified ${ }^{6}$, and may affect the quality of life $^{7-12}$ and even the prognosis of the disease. ${ }^{21}$ The mental adjustment to cancer has been extensively investigated by Greer et al. in terms of the coping strategies adopted by patients. ${ }^{13}$ An initial prospective study of subjects with early breast cancer showed that the disease free survival at five years was significantly more frequent among those women who initially reacted by denial or fighting spirit, rather than by stoic acceptance or feelings of helplessness and hopelessness. ${ }^{13}$ In a larger cohort subsequently examined, helplessness-hopelessness identified using the MAC scale, and depression measured by the HADS scale, were shown to be significant prognostic factors for the decreased survival. ${ }^{14}$

The aim of the present prospective study has been therefore to examine in women with early breast cancer the role of 5-HTTLPR polymorphism in relation to mental adaptation to cancer, and to depression and anxiety. A group of women who had received the diagnosis of mammary carcino$\mathrm{ma}$, and had been treated with surgery and adjuvant therapy, has been genotypically characterized for 5-HTTLPR. The presence of the functional $A>G$ variation within the $\mathrm{L}$ allele of SERT polymorphism, which has been reported to modulate the role of 5-HTTLPR for depression ${ }^{22,23}$, has been also examined. At the time of recruitment and at followup one and three months later, these patients were psychometrically characterized using Mini-MAC for evaluating their mental adaptation to cancer, and HADS for assessing depression and anxiety. The data obtained have been analyzed in order to identify the occurrence of associations between the psychometric variables obtained and the patients' 5-HTTLPR genotypic characteristics of the patients; the results obtained are hereafter reported.

\section{Patients and methods}

The study population consisted of women who received a diagnosis of mammary carcinoma, and who were referred to the Centro Sociale Oncologico, Azienda Servizi Sanitari 1, Trieste, Italy, between February 2008 and August 2009. The patients were recruited after the communication of the cancer diagnosis and surgery and before the beginning of adjuvant treatment (average time $135 \pm 9.7$ days), and were evaluated at enrolment into the study (T0), and at follow up one (T1) and three (T2) months later.

The study was carried out in accordance with the Declaration of Helsinki and Good Clinical Practice Guidelines, after having been approved by the relevant institutional Ethical Committee, and having received the informed consent by each participant. Conflicts of interest do not appear to exist according to the statements of the authors.

The subjects were characterized psychometrically by a trained psychologist using the Hospital Anxiety and Depression Scale (HADS) ${ }^{24}$, and the Mini Mental Adjustment to Cancer Scale (Mini$\mathrm{MAC})^{10}$ to examine the mechanisms of psychological adaptation to the disease. HADS is a 14-item questionnaire measuring anxiety (7 items) and depression (7 items), and is designed for the use in medical outpatients. HADS has been used in general psychiatry ${ }^{25}$ and in cancer settings indicating its usefulness, reliability and validity. The Mini-MAC is a 29-item questionnaire measuring patients'coping with cancer (fighting spirit, avoidance, hopelessness, anxious preoccupation and fatalism) The Mini-MAC was chosen as the primary outcome measure and the validated Italian version of mini-MAC was employed in this study. ${ }^{10,11}$

The patients were also characterized for the 5-HTTLPR polymorphism as described below. 
Subjects older than 75 years, and those with a previous history of psychopathology such as psychotic or endogenous major depressive disorder, were not included in the study. For each patient, the demographic, as well as the previous and current medical history, were recorded for the later analysis.

Genomic DNA was obtained from whole blood or buccal cells, using standard procedures (MasterAmp ${ }^{\mathrm{TM}}$ buccal swab brushes, Epicentre Technologies; GenElute $^{\mathrm{TM}}$ blood Genomic DNA Kit, Sigma).

Polymerase chain reaction (PCR) amplification of the DNA region of 5-HTTLPR was performed using the primers described by Gelernter et al. ${ }^{26}$, and with the GC-Rich PCR System (Roche Molecular Biomedicals) in a $50-\mu \mathrm{L}$ reaction containing 20-100 ng of DNA; $100 \mu \mathrm{m}$ deoxyribonucleoside triphosphate (dNTPs), 20 pmol for each primer, and $1.5 \mathrm{mM} \mathrm{MgCl}$. DNA was denatured at $95^{\circ} \mathrm{C}$ for $10 \mathrm{~min}$ and subjected to 40 cycles of $40 \mathrm{~s}$ denaturation at $94^{\circ} \mathrm{C}, 45 \mathrm{~s}$ annealing at $56^{\circ} \mathrm{C}, 40 \mathrm{~s}$ extension at $72^{\circ} \mathrm{C}$, and $10 \mathrm{~min}$ final extension at $72^{\circ} \mathrm{C}$. The products of PCR amplification were separated on a $2 \%$ agarose gel, and were visualised in ultraviolet light after ethidium bromide staining.

The presence of the functional $A>G$ variation in the long (L) allele identified by $\mathrm{Hu}$ et al. ${ }^{23}$ as the $\mathrm{La}$ and $\mathrm{Lg}$ alleles, was also evaluated by digestion of the PCR products with the Hpa II enzyme. The digested mixture was size-fractioned on agarose gel and visualised in ultraviolet light after ethidium bromide staining.

A statistical analysis was carried out using descriptive statistic, Pearson correlation and Analysis of Variance (ANOVA) to characterize the sample and to evaluate the relationships of the psychometric scales scores as a function of follow-up time and of 5-HTTLPR genotypic variants, using the SPSS 13.0 package (SPSS Inc. Chicago, IL, USA), as indicated in the Tables. Statistical significance was set at the $p<0.05$ level.

\section{Results}

The patients' socio-demographic data and clinical characteristics are illustrated in Table 1. The patients considered were initially subjected at recruitment to psychometrical evaluation (T0: $\mathrm{N}=48$ ), and were re-tested psychometrically at follow up one month after recruitment (T1: $\mathrm{N}=48$ ); a third evaluation (T2: $\mathrm{N}=35$ ) three months after $\mathrm{T} 0$ could be performed on $35(72.9 \%)$ of the initial 48 patients.

The allelic variants of 5-HTTLPR polymorphism of the subjects considered are shown in Table 2.
TABLE 1. Socio-demographic and clinical characteristics of the patients

\begin{tabular}{lc}
\hline & $\begin{array}{c}\text { Patients } \\
\mathbf{N}=\mathbf{4 8}\end{array}$ \\
\hline SOCIO-DEMOGRAPHIC CHARACTERISTICS & \\
\hline Age (mean \pm S.E.) & $60.2 \pm 1.33$ \\
Min-max & $37-73$ \\
$30-39$ & $1(2.1 \%)$ \\
$40-49$ & $8(16.7 \%)$ \\
$40-59$ & $7(14.6 \%)$ \\
60-69 & $27(56.3 \%)$ \\
70-79 & $5(10.4 \%)$ \\
\hline Employment status & \\
\hline Employed & $16(33.3 \%)$ \\
Unemployed & $9(18.8 \%)$ \\
Retired & $23(47.9 \%)$ \\
\hline Marital status & \\
\hline Married & $34(70.8 \%)$ \\
Single & $2(4.2 \%)$ \\
Divorced/Separated & $3(15.8 \%)$ \\
Widowed & $8(16.7 \%)$ \\
\hline Education completed & \\
\hline Primary school & $7(14.6 \%)$ \\
Secondary school & $12(25.0 \%)$ \\
Professional school & $9(18.8 \%)$ \\
\hline High school & $20(41.7 \%)$ \\
\hline
\end{tabular}

\begin{tabular}{lc}
\hline CLINICAL CHARACTERISTICS & \\
\hline Grading & $7(14.6 \%)$ \\
\hline 1 & $31(64.6 \%)$ \\
2 & $10(20.8 \%)$ \\
3 & \\
\hline Disease stage & $1(2.1 \%)$ \\
\hline- & $23(47.9 \%)$ \\
I & $20(41.7 \%)$ \\
II & $4(8.3 \%)$ \\
III & \\
\hline Surgery & $2(4.2 \%)$ \\
\hline No surgery & $1(2.1 \%)$ \\
Tumorectomy & $34(70.8 \%)$ \\
Quadrantectomy & $11(22.9)$ \\
Mastectomy & \\
\hline Treatment & $16(33.3 \%)$ \\
\hline Chemotherapy & $36(75 \%)$ \\
Radiation therapy & $34(70.8 \%)$ \\
Hormonal therapy & 0 \\
\hline Biological therapy &
\end{tabular}


TABLE 2. 5-HTTLPR allelic variants of the patients

\begin{tabular}{ccccc}
\hline & Allelic variant & Functionality* & N & \% \\
\hline \hline \multirow{3}{*}{5 -HTTLPR } & "short" (S) & Low & 3 & 6.3 \\
& "short-long" (S/L) & Low & 26 & 54.2 \\
& "long" (L/L) & High & 19 & 39.6 \\
\hline
\end{tabular}

- The functional activity is classified as indicated by Lesch (Lesch et al., 1996)

None of the patients had an Lg allele; the genotypic distribution for 5-HTTLPR did not significantly differ from the Hardy-Weinberg equilibrium $\left(\chi^{2}=2.30 ; p=0.13\right)$.

The psychometric measures performed were initially analyzed to determine the possible existence of difference attributable to the socio-demographic and clinical characteristics of the patients. When the scores of subscale employed were stratified for age, employment and marital status, education, disease stage and treatment, no significant differences were observed at recruitment (T0). Six out of 48 patients were receiving at recruitment an antidepressant treatment which had been prescribed before recruitment into this study, and 12 patients were treated with benzodiazepines. These groups displayed at $\mathrm{T} 0$ and $\mathrm{T} 1$ scores for depression (HADS) higher than the untreated ones; in both cases, the difference was not significant also when examined at follow up. Any reduction with time of anxiety and depression observed during the present study cannot consequently be ascribed to differences existing at recruitment, and to the drug treatments performed.

The data obtained using Mini-MAC are reported in Table 3. The scores of Mini-MAC sub-scale for anxious preoccupation displayed a decrease with time of follow up, and the analysis with ANOVA showed a significant effect of time $(F=5.646$, $d f=2.128, p=0.004)$ and genotype $(F=5.296, d f=2.128$, $p=0.023$ ). For Mini-MAC avoidance scores, ANOVA showed a significant effect of time only $(F=3.107$, $d f=2.128, p=0.048$ ).

The psychometric scores obtained using HADS at T0, T1 and T2 are illustrated in Table 4. For both HADS subscales, no statistically significant effects of time and genotype were observed.

\section{Discussion}

The initial findings of Caspi et al. on the role played by the 5-HTTLPR genetic polymorphism of serotonin transporter in modulating the appear- ance of depression after stressful life-events was initially not supported by the results of the metaanalysis performed in 2009 by Riesch et al. ${ }^{27}$, and by Munafò et al...28 Moreover, Middeldorp et al., in a study conducted on series of twins, were unable to demonstrate any significant interaction between 5-HTTLPR polymorphism and the number of life events experienced across the life span or the year preceding the depressive episode. ${ }^{29} \mathrm{~A}$ subsequent meta-analysis, where the small number of studies previously considered was increased has been recently published, provided support, in contrast to the results of the these earlier studies, for the hypothesis that 5-HTTLPR influences the relationship between stress and depression. ${ }^{30}$

The aim of the present study was that to examine in cancer patients the role of 5-HTTLPR in the mental adaptation to the disease, where diagnosis and treatment were considered to be the stressful life events requiring adequate coping by the patients. When the role of 5-HTTLPR in relation to mental adaptation to cancer has been examined by us in a recent previous occasion previously, the baseline HADS and mini-MAC scores measured at recruitment in a different sample of women with early breast cancer were found not to depend on the genetic polymorphism of serotonin transporter. ${ }^{31}$

The evaluation of the patients' conditions at first assessment (T0) indicates no significant difference in the score of any of the psychometric scales employed when the patients are grouped according to their SERT genotypic variant. An improvement with time, not dependent on 5-HTTLPR, appeared for the avoidance scores of Mini-Mac. The results presented here also indicate that the scores of anxious preoccupation, as identified using Mini-MAC, significantly depended on the genotype of SERT. Moreover, a gene - environment interaction appears for the anxious preoccupation scores, which significantly decreased with the time of follow up, in a way more pronounced in the group of patients carriers of the $\mathrm{L} / \mathrm{L}$ genetic variant as compared with the carriers of at least one $S$ allele $\left(r^{2}=0.17\right.$ v.s. $r^{2}=0.04, p=0.002$ ). The enrolled women were further characterized for the L and S variants of 5-HTTLPR genetic polymorphism, also considering the triallelic 5-HTTLPR classification; none of the patients presently investigated had an Lg allele, which is not further considered.

These results support the view that anxious preoccupation plays a significant role in patients with non advanced breast cancer during the early phase of the treatment of the disease. In this connection, several studies showed that an increased anxious 
TABLE 3. Subscale scores of MINI-MAC in relation to time and 5-HTTLPR genotype

\begin{tabular}{|c|c|c|c|c|c|c|}
\hline & Allelic variants & $\begin{array}{c}\text { TO } \\
\text { mean } \pm \text { SEM }\end{array}$ & $\begin{array}{c}\mathrm{T1} \\
\text { meantSEM }\end{array}$ & $\begin{array}{c}\text { T2 } \\
\text { mean } \pm \text { SEM }\end{array}$ & $\begin{array}{c}\text { Effect of Time } \\
p^{a}\end{array}$ & $\begin{array}{c}\text { Effect } \\
\text { of genotype } \\
\mathrm{p}^{\mathrm{b}}\end{array}$ \\
\hline \multirow{2}{*}{$\begin{array}{l}\text { Hopelessness- } \\
\text { Helplessness }\end{array}$} & $S / S-S / L-L / L$ & $11.94 \pm 0.58(\mathrm{~N}=48)$ & $11.67 \pm 0.53(\mathrm{~N}=48)$ & $11.06 \pm 0.64(\mathrm{~N}=35)$ & .581 & \multirow{2}{*}{.692} \\
\hline & $\mathrm{L} / \mathrm{L}$ & $12.05 \pm 1.01(N=19)$ & $11.74 \pm 0.78(\mathrm{~N}=19)$ & $10.38 \pm 0.61 \quad(N=16)$ & .353 & \\
\hline \multirow{2}{*}{ Fighting spirit } & $S / S-S / L-L / L$ & $14.17 \pm 0.37(N=48)$ & $14.25 \pm 0.28(N=48)$ & $14.20 \pm 0.47(\mathrm{~N}=35)$ & .986 & \multirow{3}{*}{.455} \\
\hline & $\mathrm{L} / \mathrm{L}$ & $14.16 \pm 0.71 \quad(N=19)$ & $14.21 \pm 0.52(\mathrm{~N}=19)$ & $13.63 \pm 0.78(\mathrm{~N}=16)$ & .803 & \\
\hline \multirow{3}{*}{ Fatalism } & $S / S-S / L-L / L$ & $9.35 \pm 0.35(\mathrm{~N}=48)$ & $9.04 \pm 0.32(N=48)$ & $8.94 \pm 0.31(N=35)$ & .663 & \\
\hline & S/S-S/L & $9.14 \pm 0.43(\mathrm{~N}=29)$ & $8.97 \pm 0.43(N=29)$ & $8.95 \pm 0.44(N=19)$ & .942 & \multirow{2}{*}{.520} \\
\hline & $\mathrm{L} / \mathrm{L}$ & $9.68 \pm 0.61(N=19)$ & $9.16 \pm 0.49(N=19)$ & $8.94 \pm 0.44(N=16)$ & .595 & \\
\hline $\begin{array}{l}\text { Anxious preoc- } \\
\text { cupation }\end{array}$ & $S / S-S / L-L / L$ & $15.71 \pm 0.70(\mathrm{~N}=48)$ & $13.50 \pm 0.65(N=48)$ & $12.51 \pm 0.67(\mathrm{~N}=35)$ & .004 & .023 \\
\hline \multirow[t]{2}{*}{ Avoidance } & S/S-S/L & $11.00 \pm 0.65(\mathrm{~N}=29)$ & $9.31 \pm 0.53(\mathrm{~N}=29)$ & $9.68 \pm 0.65(N=19)$ & .105 & \multirow{2}{*}{.698} \\
\hline & $L / L$ & $10.47 \pm 0.65(N=19)$ & $9.79 \pm 0.66(N=19)$ & $9.13 \pm 0.60(N=16)$ & .352 & \\
\hline
\end{tabular}

The data reported are the mean \pm SEM of the psychometric scores at recruitment (TO), after one month (T1) and three months (T2)

The data were analyzed with the analysis of variance (ANOVA), testing the effect of time ${ }^{a}$ and of genetic polymorphism ${ }^{b}$ as independent variables; statistical significance was set at $p<0.05$ level

preoccupation, as determined with the Mini-MAC scale, was significantly associated with evidence of psychological stress symptoms, and appeared to be the most significant indicator of patients' difficulties in mental adjustment to cancer. ${ }^{10,32-34}$ These findings are also in agreement with a feasibility study of psychosocial intervention in women with early breast cancer, which indicated high baseline values of anxious preoccupation HADS scores, which could be reduced by a psycho-educational intervention $^{35}$ based on the approach originally devised by Fawzy and Fawzy for melanoma patients. ${ }^{36}$

The data reported so far indicate that the scores of anxious preoccupation decrease spontaneously with time at follow up, indicating that coping and mental adaptation to the initial diagnosis and to the adjuvant therapy were occurring. The significance of the reduction of avoidance scores appears less clear, since this style of coping has been identified as a risk factor for the poor general mental adjustment and disease progression ${ }^{37-39}$, and has been suggested to be adaptive in the short run, but maladaptive for the long-term adjustment. ${ }^{40}$

The decrease with time of anxious preoccupation significantly depended on SERT polymorphism, and was less pronounced in women carrying one or two $S$ alleles; these patients appeared to be those in greater need of intervention. The available literature indicates that psycho-social or psycho-educational interventions ${ }^{36,41-44}$, or drug treatment ${ }^{45-47}$ might be indicated. The data presently reported suggest that the individual molecular-genetic information concerning 5-HTTLPR polymorphism can be usefully considered for identifying the patients at greater risk of anxious preoccupation, and may be considered for the choice of the agent in case of drug treatment on the basis of the pharmacogenetic evidence available. The implications for the choice of the possible treatment of the patients with anxiolytic or antidepressant drugs, which are indicated also for conditions involving an anxious component $\mathrm{t}^{48}$ as an alternative to psycho-educational intervention, are interesting. The review of the pharmacogenetic of selective serotonin reuptake inhibitor (SSRI) antidepressants indicates that a greater incidence of adverse effects, and presumably a lesser therapeutic response, is likely to occur in carriers of S alleles of 5-HTTLPR variants of serotonin transporter. ${ }^{45,48}$ When the drug treatment is the choice of intervention for treating difficulties of mental adaptation to cancer, benzodiazepines or antidepressant agents with a mechanism of action different from that of SSRIs ${ }^{49,50}$ should be considered in the perspective of a personalized 
TABLE 4. Subscale scores of HADS in relation to time and 5-HTTLPR genotype

\begin{tabular}{|c|c|c|c|c|c|c|}
\hline & Allelic variants & $\begin{array}{c}\text { TO } \\
\text { mean } \pm S E M\end{array}$ & $\begin{array}{c}\mathrm{T} 1 \\
\text { mean } \pm S E M\end{array}$ & $\begin{array}{c}\text { T2 } \\
\text { mean } \pm S E M\end{array}$ & $\begin{array}{l}\text { Effect of Time } \\
\qquad p^{a}\end{array}$ & $\begin{array}{c}\text { Effect } \\
\text { of genotype } \\
p^{b}\end{array}$ \\
\hline \multirow{3}{*}{ Depression } & $S / S-S / L-L / L$ & $4.15 \pm 0.46(N=48)$ & $3.10 \pm 0.38(\mathrm{~N}=48)$ & $2.97 \pm 0.50(\mathrm{~N}=35)$ & .124 & \multirow{4}{*}{.429} \\
\hline & $S / S-S / L$ & $4.31 \pm 0.60(\mathrm{~N}=29)$ & $3.14 \pm 0.51 \quad(N=29)$ & $3.32 \pm 0.77(N=19)$ & .318 & \\
\hline & $\mathrm{L} / \mathrm{L}$ & $3.89 \pm 0.75(\mathrm{~N}=19)$ & $3.05 \pm 0.59(N=19)$ & $2.56 \pm 0.62(\mathrm{~N}=16)$ & .365 & \\
\hline \multirow{3}{*}{ Anxiety } & $S / S-S / L-L / L$ & $4.56 \pm 0.59(\mathrm{~N}=48)$ & $3.60 \pm 0.49(N=48)$ & $3.37 \pm 0.62(\mathrm{~N}=35)$ & .288 & \\
\hline & $S / S-S / L$ & $5.41 \pm 0.83(\mathrm{~N}=29)$ & $3.90 \pm 0.60(N=29)$ & $4.21 \pm 0.97(\mathrm{~N}=19)$ & .325 & \multirow{2}{*}{.170} \\
\hline & $\mathrm{L} / \mathrm{L}$ & $3.26 \pm 0.69(\mathrm{~N}=19)$ & $3.16 \pm 0.85(\mathrm{~N}=19)$ & $2.38 \pm 0.69(\mathrm{~N}=16)$ & .681 & \\
\hline
\end{tabular}

The data reported are the mean \pm SEM of the psychometric scores at recruitment (TO), after one month (T1) and three months (T2)

The data were analyzed with the analysis of variance (ANOVA), testing the effect of time ${ }^{a}$ and of genetic polymorphism ${ }^{b}$ as independent variables; statistical significance was set at $p<0.05$ level

and more effective treatment. A focussed attention thus might be given to pharmacogenetics, together with consideration to possible pharmacokinetic or pharmacodynamic interactions between the drugs received by the patients ${ }^{51}$, such as those already reported for SSRIs and tamoxifen. ${ }^{52,53}$

The further research extended to include a larger cohort of patients, appears to be encouraged by the results reported and is currently being performed by the authors in the perspective of a further investigation of mental adaptation to cancer in relation to the genetic and cultural ethnic milieu of the patients, including the goal of a personalized and more effective intervention.

\section{Acknowledgements}

This work was made possible by the generous contribution of Fondazione Benefica Alberto \& Kathleen Foreman Casali and of Beneficentia Stiftung Lichtenstein, was supported by the "Programma di Ricerca Scientifica di Interesse Nazionale of Italian Ministero dell'Istruzione, dell'Università e della Ricerca" entitled "Phenotypic and genotypic characterization of mental adaptation to cancer and of the response to the treatment with antidepressant drugs in oncology (Anno 2007 - prot. 20074XMRSE) "and by Azienda per I Servizi Sanitari $N^{\circ} 1$, Trieste, Italy.

\section{References}

1. Stanton AL, Danoff-Burg S, Huggins M. The first year after breast cancer diagnosis: hope and coping strategies as predictors of adjustment. Psychooncology 2002; 11: 93-102.

2. Ozalp E, Soygu H, Cankurtaran E, Turhan L, Akbyk D, Geyik P. Psychiatric morbidity and its screening in Turkish women with breast cancer: a comparison between the HADS and SCID tests. Psychooncology 2008; 17: 668-75. Lueboonthavatchai P. Prevalence and psychosocial factors of anxiety and depression in breast cancer patients. J Med Assoc Thai 2007; 90: 2164-74.
3. Boehmke MM, Dickerson SS. The diagnosis of breast cancer: transition from health to illness. Oncol Nurs Forum 2006, 33: 1121-7.

4. Fertig DL. Depression in patients with breast cancer: prevalence, diagnosis, and treatment. Breast J 1997; 5: 292-302.

5. Holland JC, Mastrovito R. Psychologic adaptation to breast cancer. Cancer. 1980; 46(4 Suppl): 1045-52.

6. Akechi T, Okuyama T, Imoto S, Yamawaki S, Uchitomi Y. Biomedical and psychosocial determinants of psychiatric morbidity among postoperative ambulatory breast cancer patients. Breast Cancer Res Treat 2001; 65: 195-202.

7. Matsuoka $Y$, Nakano $T$, Inagaki $M$, Sugawara $Y$, Akechi $T$, Imoto $S$, et al. Cancer-related intrusive throughs as an indicator of poor psychological adjustment at 3 or more years after breast surgery: a preliminary study. Breast Cancer Res Treat 2002; 76: 117-24.

8. Cordova MJ, Giese-Davis J, Golant M, Kronnenwetter C, Chang V, Mc Farlin $\mathrm{S}$, et al. Mood disturbance in community cancer support groups. The role of emotional suppression and fighting spirit. J Psychosomatic Res 2003; 55: 461-7.

9. Grassi L, Buda P, Cavana L, Annunziata MA, Torta R, Varetto A. Styles of coping with cancer: The Italian version of the Mini-Mental Adjustment to Cancer (Mini-Mac) scale. Psychooncology 2005; 14: 115-24.

10. Grassi L, Travado L, Moncayo FLG, Sabato S, Rossi E and the SEPOS group. Psychosocial morbidity and its correlates in cancer patients of the Mediterranean area: findings from the Southern European PsychoOncology Study. J Affect Disord 2004; 83: 243-8.

11. Bloom JR, Stewart SL, Johnston M, Banks P, Fobair P. Sources of support and the physical and mental well being of young women with breast cancer. Soc Sci Med 2001; 53: 1513-24.

12. Greer S, Morris T, Pettingale KW. Psychological response to breast cancer: effect on outcome. Lancet 1979; 2: 785-7.

13. Watson M, Haviland JS, Greer S, Davidson J, Bliss JM. Influence of psychological response on survival in breast cancer: a population-based cohort study. Lancet 1999; 354: 1331-6.

14. Erculj N, Kovac V, Hmeljak J, Dolzan V. The influence of platinum pathway polymorphisms on the outcome in patients with malignant mesothelioma. Ann Oncol 2012; 23: 461-7.

15. Erčulj N, Kovač V, Hmeljak J, Franko A, Dodič-Fikfak M, Dolžan V. The influence of gemcitabine pathway polymorphisms on treatment outcome in patients with malignant mesothelioma. Pharmacogenet Genomics 2012; 22: 58-68.

16. Caspi A, Sugden K, Moffitt TE, Taylor A, Craig IW, Harrington H, et al. Influence of life stress on depression: moderation by a polymorphism in the 5-HTT gene. Science 2003; 301: 386-9.

17. Lesch KP, Bengel D, Heils A, Sabol SZ, Greenberg BD, Petri S, et al. Association of anxiety-related traits with a polymorphism in the serotonin transporter gene regulatory region. Science 1996; 274: 1527-31.

18. Plesnicar A, Golicnik M, Fazarinc IK, Kralj B, Kovac V, Plesnicar BK. Attitudes of midwifery students towards teaching brast-self examination. Radiol Oncol 2010; 44: 52-6. 
19. Ovcaricek T, Frkovic SG, Matos E, Mozina B, Borstnar S. Triple negative breast cancer - prognostic factors and survival. Radiol Oncol 2011; 45: 46-52.

20. Andersen B, William B, Farrar WB, Golden-Kreutz D, Kutz LA, Courtney ME, et al. Stress and immune responses after surgical treatment for regional breast cancer. J Natl Cancer Inst 1998; 90: 30-6.

21. Zalsman G, Huang $Y$, Oquendo MA, Burke AK, $\mathrm{Hu} X$, Brent DA, et al. Association of a triallelic serotonin transporter gene promoter region (5-HTTLPR) polymorphism with stressful life events and severity of depression. Am J Psychiatry 2006; 163: 1588-93.

22. Hu XZ, Lipsky RH, Zhu G, Akhtar LA, Taubman J, Greenberg BD, et al. Serotonin transporter promoter gain-of-function genotypes are linked to obsessive-compulsive disorder. Am J Hum Genet 2006; 78: 815-26.

23. Zigmond AS, Snaith RP. The Hospital Anxiety and Depression Scale. Acta Psychiatr Scand 1983; 67: 361-70.

24. Garcia-Cebrian A, Bauer M, Montejo AL, Dantchev N, Demyttenaere K, Gandhi P, et al. Factors influencing depression endpoints research (FINDER): Study design and population characteristics. European Psychiatry 2008; 23: $57-65$.

25. Gelernter J, Kranzler H, Cubbels JF. Serotonin transporter protein (SLC6A4) allele and haplotype frequencies and linkage disequilibria in African and European-American and Japanese populations and in alcohol-dependent subjects. Hum Genet 1997; 101: 243-6.

26. Risch N, Herrell R, Lehner T, Liang $K Y$, Eaves L, Hoh J, et al. Interaction between the serotonin transporter gene (5-HTTLPR), stressful life events, and risk of depression: a meta-analysis. JAMA 2010; 301: 2462-71.

27. Munafò MR, Freimer NB, Ng W, Ophoff R, Veijola J, Miettunen J, et al. 5-HTTLPR genotype and anxiety-related personality traits: a meta-analysis and new data. Am J Med Genet B 2009; 150: 271-81.

28. Middeldorp CM, de Geus EJ, Willemsen G, Hottenga JJ, Slagboom PE, Boomsma DI. The serotonin transporter gene length polymorphism (5-HTTLPR) and life events: no evidence for an interaction effect on neuroticism and anxious depressive symptoms. Twin Res Hum Gen 2010; 13: 544-9.

29. Karg K, Burmeister M, Shedden K, Sen S. The Serotonin Transporter Promoter Variant (5-HTTLPR), Stress, and Depression Meta-analysis Revisited: Evidence of Genetic Moderation. Arch Gen Psychiat 2011; 68: 444-54.

30. Grassi L, Rossi E, Cobianchi M, Aguiari L, Capozzo MA, et al. Depression and serotonin transporter (5-HTTLPR) polymorphism in breast cancer patients. J Affect Disord 2010; 124: 346-50.

31. Kash KM, Mago R, Kunkel E. Psychosocial oncology: supportive care for the cancer patients. Semin Oncol 2004; 32: 211-8.

32. Ho SM, Fung WK, Chan CL, Watson M, Tsui YK. Psychometric properties of the Chinese version of the Mini-Mental Adjustment to Cancer (MINIMAC) scale. Psychooncology 2003; 12: 547-56.

33. Anagnostopoulos F, Kolokotroni P, Spanea E, Chryssochoou M. The minimental adjustment to cancer (mini-MAC) scale: construct validation with a Greek sample of breast cancer patients. Psychooncology 2006; 15: 79-89.

34. Capozzo MA, Martinis E, Pellis G, Giraldi T. An early structured psychoeducational intervention in breast cancer patients: results from a feasibility study. Cancer Nurs 2010; 33: 228-34.

35. Fawzy Fl, Fawzy NW. A structured psychoeducational intervention for cancer patients. Gen Hosp Psychiatry 1994; 16: 149-52.

36. Carver CS, Pozo C, Harris SD. How coping mediates the effect of optimism on distress: A study of women with early stage breast cancer. J Pers Soc Psychol 1993; 65: 375-90.

37. Osowiecki D, Compas BE. Psychological adjustment to cancer: Control beliefs and coping in adult cancer patients. Cog Ther Res 1998; 22: 483-99.

38. Stanton AL, Danoff-Burg S, Cameron CL. Emotionally expressive coping predicts psychological and physical adjustment to breast cancer. J Consul Clin Psychol 2000; 68: 875-82.

39. Roth S, Cohen $\sqcup$. Approach, avoidance, and coping with stress. Am Psychol 1986; 41: 813-9.

40. Fukui S, Kugaya A, Okamura $H$, Kamiya M, Koike M, Nakanishi T, et al. A psychosocial group intervention for Japanese women with primary breast cancer: a randomized controlled trial. Cancer 2000; 89: 1026-36.
41. Weis J. Support groups for cancer patients. Support Care Cancer 2003; 11: $763-8$

42. Kissane D, Bloch S, Smith GC, Miach P. Cognitive-existential group psychotherapy for women with primary breast cancer: a randomised controlled trial. Psychooncology 2003; 12: 532-46.

43. Maeda T, Kurihara H, Morishima I, Munakata T. The effect of psychological intervention on personality change, coping, and psychological distress of Japanese primary breast cancer patients. Cancer Nurs 2008; 31: 27-35.

44. Smits K, Smits L, Peeters F, Schouten J, Janssen R, Smeets H, et al. Serotonin transporter polymorphisms and the occurrence of adverse events during treatment with selective serotonin reuptake inhibitors. Int Clin Psychopharm 2007; 22: 137-43.

45. Schillani G, Capozzo MA, Aguglia E, De Vanna, M, Grassi L, Conte MA, et al. 5-HTTLPR polymorphism of serotonin transporter and effects of sertraline in terminally ill cancer patients: report of eleven cases. Tumori 2008; 94: 563-7.

46. Capozzo MA, Schillani G, Aguglia E, De Vanna M, Grassi L, Conte MA, et al. Serotonin transporter 5-HTTLPR polymorphism and response to citalopram in terminally ill cancer patients: report of twenty-one cases. Tumori 2009; 95: 479-83.

47. Kato M, Serretti A. Review and meta-analysis of antidepressant pharmacogenetic findings in major depressive disorder. Mol Psychiatr 2010; 15: 473-500.

48. Bandelow B, Andersen HF, Dolberg OT. Escitalopram in the treatment of anxiety symptoms associated with depression. Depress Anxiety 2007; 24: 53-6.

49. Cankurtaran ES, Ozalp E, Soygur H, Akbiyik DI, Turhan L, Alkis N. Mirtazapine improves sleep and lowers anxiety and depression in cancer patients: superiority over imipramine. Support Care Cancer 2008; 16: 1291-8.

50. Caraci F, Crupi R, Drago F, Spina E. Metabolic drug interactions between antidepressants and anticancer drugs: focus on selective serotonin reuptake inhibitors and hypericum extract. Curr Drug Metab 2011; 12: 570-7.

51. Kelly CM, Juurlink DN, Gomes T, Duong-Hua M, Pritchard KI, Austin PC, et al. Selective serotonin reuptake inhibitors and breast cancer mortality in women receiving tamoxifen: a population based cohort study. BMJ 2010; 340: $c 693$

52. In brief: Tamoxifen and SSRI interaction. Med Lett Drugs Ther. 2009; 51(1314): 45 